\title{
Application of Sandwich Learning in the Theory Teaching of Histology and Embryology for First-Year Medical Students
}

\author{
Jinhua Wang1,2*, Liqing Li ${ }^{3}$, Hai Li'1, Chunying Luo', Jianhai Chen', Xiaoyan Fang1, \\ Yongzhi Huang1, Qiongzhi Zhao', Hailing Huang1, Qichuan Huang1, \\ Biao Li1, Qianli Tang1 ${ }^{*}$ \\ ${ }^{1}$ Youjiang Medical University for Nationalities, Baise, China \\ ${ }^{2}$ West China School of Basic Medical Sciences \& Forensic Medicine, Sichuan University, Chengdu, China \\ ${ }^{3}$ Graduate School, Hunan University of Chinese Medicine, Changsha, China \\ Email: ^28516758@qq.com, ${ }^{\star}$ htmgx@163.com
}

How to cite this paper: Wang, J. H., Li, L. Q., Li, H., Luo, C. Y., Chen, J. H., Fang, X. Y., Huang, Y. Z., Zhao, Q. Z., Huang, H. L., Huang, Q. C., Li, B., \& Tang, Q. L. (2018). Application of Sandwich Learning in the Theory Teaching of Histology and Embryology for First-Year Medical Students. Creative Education, 9, 1637-1647.

https://doi.org/10.4236/ce.2018.911118

Received: June 9, 2018

Accepted: August 28, 2018

Published: August 31, 2018

Copyright $\odot 2018$ by authors and Scientific Research Publishing Inc. This work is licensed under the Creative Commons Attribution International License (CC BY 4.0).

http://creativecommons.org/licenses/by/4.0/

\begin{abstract}
Objective: To investigate the effect of Sandwich Learning (SL) in the theory teaching of Histology and Embryology. Methods: 110 freshmen majoring in clinical medicine were randomly chosen as the experimental group of Sandwich Learning, while 111 students at the same grade were chosen as the control group for traditional lecture-style teaching. After different teaching, students from both groups were surveyed by questionnaires. And they had to take examinations about theoretical knowledge and specimen of Histology and Embryology. Then the same group of teachers marked all the exam papers according to the same scoring standards. Results: There were significantly differences in the averages of the final exam about theoretical knowledge, regular assignments and final scores between two groups. Difference in results of specimen assessment was not statistically significant. The questionnaire survey results showed that students affirmed the effect of sandwich learning in improving learning initiative, sense of responsibility and communication skills in study. Conclusion: The research shows that the application of Sandwich Learning has good teaching effect in theory teaching of Histology and Embryology and helps to cultivate the comprehensive ability of medical students.
\end{abstract}

\section{Keywords}

Sandwich Learning, Active Learning, Histology and Embryology 


\section{Introduction}

Sandwich learning (SL), originally developed by University of Heidelberg, is the new strategy for medical courses (Kadmon, Strittmatter-Haubold, Greifeneder, Ehlail, \& Lammerding-Koppel, 2008). Sandwich Learning is a teaching method which was named by the familiar fast food-Sandwich to express its process of interspersed learning. It is a new type of teaching method in which transformation of learning and activities were often carried out in small class teaching, interspersed with group discussion, cross learning, learning report and other activities to require constant student attendance and participation, make more communications between teachers and students, students and students, so as to mobilize students' active learning and improve their ability of self-learning, critical thinking and exploring new knowledge.

Approaches used in medical education have been changing, and a variety of new teaching strategies are now used in many schools to promote active learning (McKeachie, Svinicki, \& Hofer, 2006). Many schools have reduced the number of lectures in favor of problem-based learning (PBL) approaches (Antepohl \& Herzig, 1999). However, despite its advantages, more faculty members and classrooms are needed for PBL to be effectively implemented, so that some universities consider PBL to be too expensive. Team-based learning (TBL) is usually conducted in large group settings more than 100 students where the students are divided into multiple small groups. In addition, a TBL session can be conducted by a single instructor. Therefore, TBL consumes much less teaching resources than PBL, and is suitable for large-class teaching (Obad et al., 2016; Pogge, 2016; Seidel \& Richards, 2001; Thomas \& Bowen, 2011).

The course of Histology and Embryology (hereinafter referred to HE), belonging to the category of morphology, is one of the most important elementary compulsory courses for medical students in China. This course for the first year college students focuses on the fine structure and related functions of human body. The course content involves a large number of abstract nouns and fine structures. The school has about 2000 students studying the course each year. How can we achieve effective learning? How can we stimulate the enthusiasm and initiative of students? How can we convert the students from conventional passive acceptance of knowledge to self-construction of knowledge so as to cultivate their initial clinical thinking? All these questions are worthy of exploring for each instructor who teaches elementary medical courses. This study served to investigate whether the SL using in large classes could be adopted in the theoretical teaching of histology and embryology course. Although we know SL is suitable for small class teaching. However, the theoretical teaching class is dominated by large size. Therefore, it is necessary to explore more optional methods besides TBL to stimulate students' active learning. Sandwich learning is based on cognitivism and constructivism (Piaget, 1997). Through teachers providing information, asking questions, defining goals, and conducting a series of activities such as discussion (Salter-Dvorak, 2016), summarization, and presentation, students maintain intentional attention and unintentional attention, thus promoting stu- 
dents' active learning (Kay \& Kibble, 2016). This report describes the specific application and practice of SL in HE course, attempting to provide a practical reference for other medical morphology courses (such as Anatomy, Pathology, Microbiology, etc.) of higher medical colleges.

\section{Objects and Time}

Histology and Embryology is a 2-credit-hour course offered for Clinical majors during the second semester of the first year at the Youjiang Medical University for Nationalities. Class was scheduled over a period of 10 weeks for 2 days per week as two 40-minute. The total class 40-minute was 36. 2013 Clinical undergraduate class $7-8(111)$ as a control class was conducted by using traditional lecture method, class 9 - 10 (110) as an experimental class was conducted by using SL method. The implementation duration was the first half of 2014.

The course was divided into 7 modules (the number of allocated 40-minute): four basic tissues (10), immune system (2), endocrine system (2), digestive (4), respiratory (2), urinary (2) and reproductive (6), embryogenesis subject (8). Digestive system, urinary and reproductive system embryogenesis subjects modules were selected using SL method in experimental class.

In the beginning of the histology and embryology course, the SL procedure and grading system were explained to the students. Each module has $12.5 \%$ of the grade of the whole assignment. Common grades were determined as follows: $70 \%$ final examination score, $15 \%$ assignment, and $15 \%$ specimen evaluation.

\section{Basic Procedure}

\subsection{Pre-Class Preparations}

First, compiling Sandwich teaching plans. Teaching plan was written by senior teachers or by the teaching and research office after group discussions. The elements of teaching plans include: introductory remarks (simple and, concise animation, videos, stories, and cases as lead-ins); providing information (to provide general information about the topic); putting forward learning objectives (the objectives on knowledge, skills and awareness); raising questions (five questions were raised according to the grouping conditions of the experimental class); teaching summary (to analyze each question); putting forward new question in "goldfish bowl" (to observe student's learning effect and ability to apply knowledge to solve practical problems).

Second, grouping and numbering. Students are divided into 4 to 6 groups, each group with 4 to 6 students according to class size. One hundred of the 110 students are divided into four large groups, each of which is divided into five groups which five people form a group. The remaining 10 people form a large group, divided into 2 small groups. See specific group numbers in Figure 1.

\subsection{Process in Class}

When entering classroom, each of the 110 students got a number card, according 


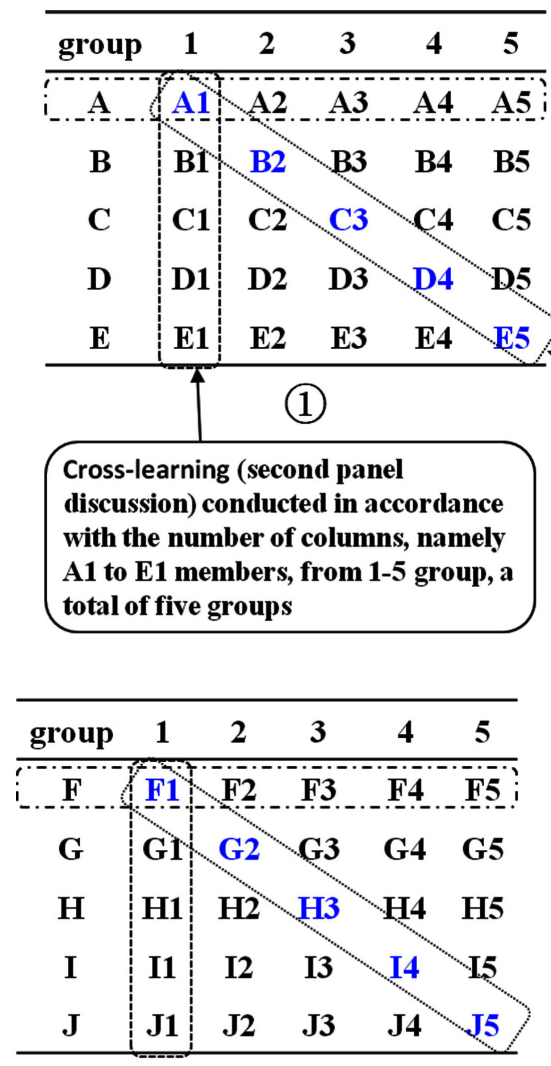

(2)

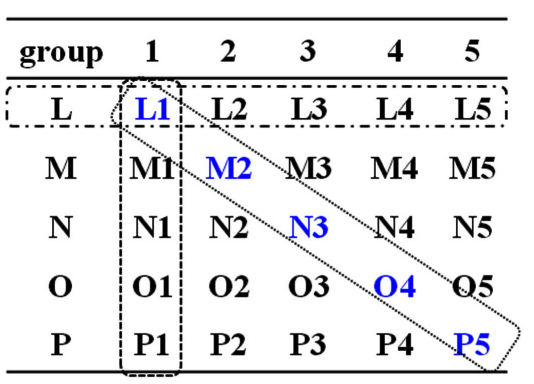

(3)

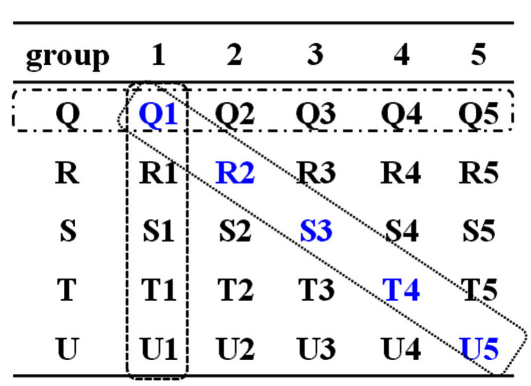

(4) were composed of 'goldfish bowl' group, express their opinions, the other students if you hold different opinions can jump "goldfish bowl" to speak at any time

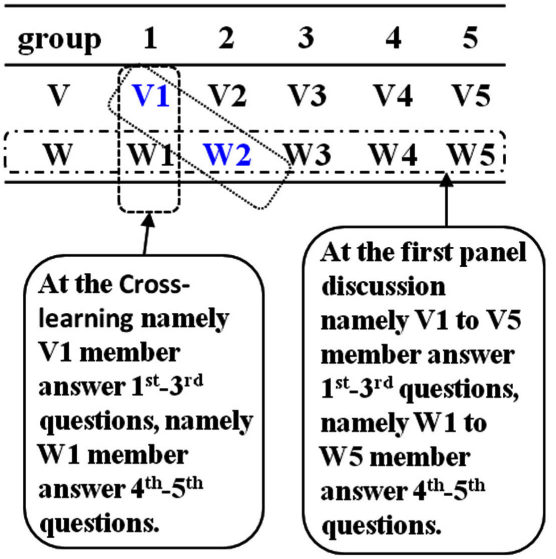

(5)

Figure 1. Instruction of grouping and numbering (taking the 110 students of experimental group as example). Large group: (1)(2)(3)(5), each large group is divided into 2 or 5 smaller group.

to which they found an assigned seat (see Figure 2). Classic SL has 8 phases (Huang, Ma, Yi, \& Fu, 2008; Wang et al., 2015), details as follows:

Phase 1 involves opening and providing information: teachers should bring out topics that are vivid and eye-catching, attracting students' attention and enhancing their interest in learning.

Phase 2 involves ask questions: the teacher simply gives general information about the topic, and at the same time proposes the learning objectives of the class; proposes 5 questions (Q1 - Q5) for each group to discuss a question, and the student enters the next self-study session (specify the discussion time, such as 20 - 30 minutes).

Phase 3 involves panel discussion: students enter the corresponding group to discuss the assigned question according to their own number.

Phase 4 involves cross-learning: after the group discussion, students with numbers 1, 2, 3, 4, and 5 are regrouped into new groups (such as A-1, B-1, C-1, D-1, E-1, and see Figure 1). Each student reports the results of their own problems in the new group. Every student must speak, everyone is trained, and the new team members can share the results of 5 questions so that everyone can understand every issue and exchanges of ideas to form new insights.

Phase 5 involves group's representative's report: the students are gathered 


\section{Teacher Activities}

Lead to the topic, stimulate the interest of learning, give simple information of learning topics, and propose learning objectives.

Present 4 to 6 problem, each group was assigned to one problem, specify the discussion time.(20 to 30 minutes)

The teacher should listen to student's discussion when they discuss, understand the difficulties of students timely during their discussion, and provide resource, methodological guidance appropriately; make a preliminary assessment of collaboration of team activities. I

Organize students to form new groups; listen to new group's report and record critical information timely to understand the situation of students to solve problem.

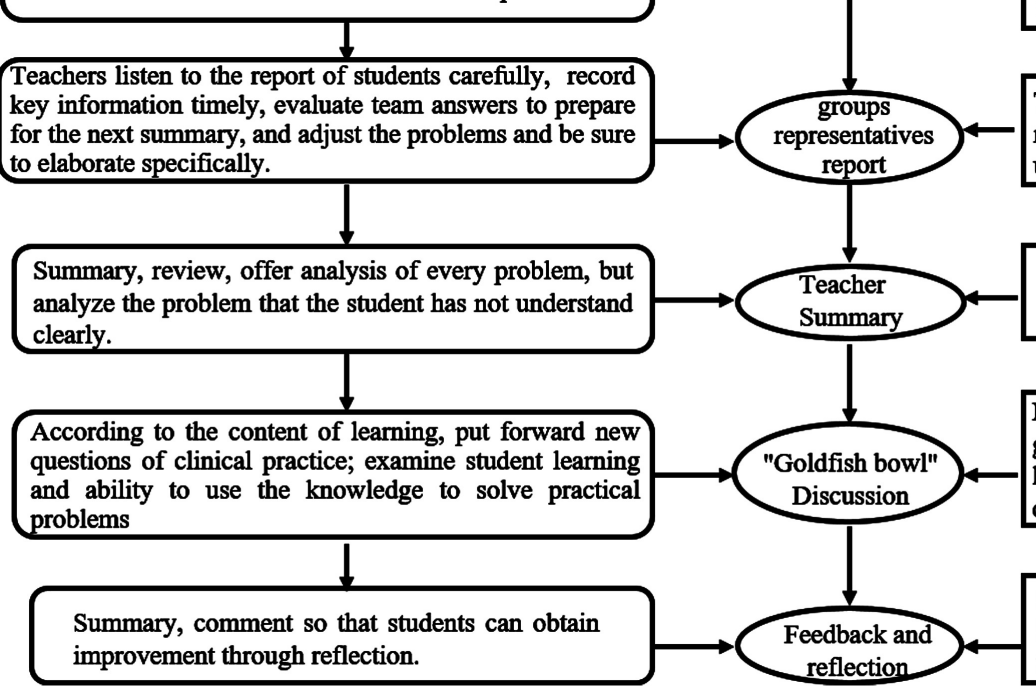

Teaching process

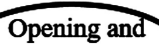
providing

information
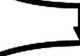

Ask questions look for information

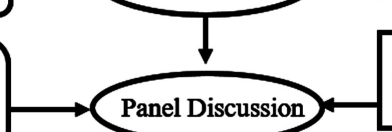

Panel Discussion

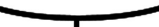
use information, get the reference and form the outline report. result of individual problem in a new group where every student must speak, has been tempered, and the new team members share the result of 4 to 6 questions, so that each person on each question has understood, interchange the new comments

The group representative report, make self-evaluation, mutual evaluation, extension, transference and mainly use the blackboard-writing method

Identify problems and analyze points; make selfassessment

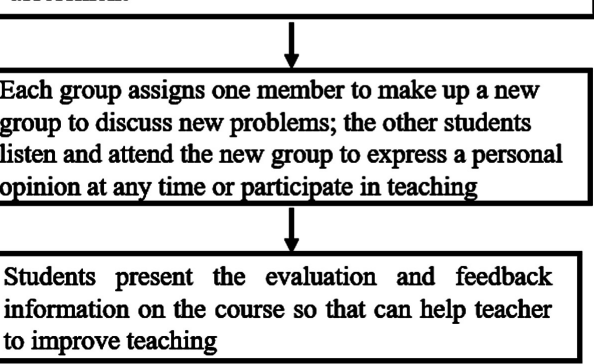

Figure 2. The frame diagram for carrying out Sandwich learning in the experimental class (drawn according to the practical situation of this study with reference to Huang Yaling and Wang Jinhua (Huang et al., 2008; Wang et al., 2015)).

again. Each group sends a representative to speak and report the results of each group's discussion. The way of speaking is in the form of a blackboard or on the UMU network platform, and the students' expression skills are also exercised.

Phase 6 involves teacher summary: teachers provide information and analyze each question around the learning objectives of this class; then, based on what they have learned, put forward clinical practical questions, test students' learning effects and use their knowledge to solve practical problems.

Phase 7 involves "Goldfish bowl" discussion: select 5 students (such as A-1, B-2, C-3, D-4, E-5) to form a new group to discuss new issues. Other students can listen or join the new group to present personal opinions and participate in the discussion at any time. During the discussion, the teacher observes the enthusiasm of the students to participate, checks whether the students master the content they are learning, and whether they can apply the knowledge they have learned and solve the clinical problems.

Phase 8 involves feedback and reflection: students provide evaluation and feedback information for this lesson so that teachers can improve. 


\subsection{Evaluation Methods}

At the end of the course, students were required to complete a survey using a series of five-point Likert-scale questions was administered to gather feedback from the students. The questionnaire consisted of 9 items (Table 1). Teachers randomly selected questions from test database, the experimental group and the control group students were required to complete the theoretical knowledge examination and specimens' assessment of Histology and Embryology. Then, the score was conducted in accordance with the scoring criteria by the same group of teachers (Table 2). Data were analyzed utilizing SPSS 18.0 software. Data using mean \pm standard deviation. Significant between-group analysis of the mean scores is to use two-tailed t test for independent samples, when the variance is used t'missing test.

\section{Results}

\subsection{The Questionnaire Results}

Overall, 110 students responded to the questionnaire. The responses to each statement are shown in Table 2. Survey results show that students are surer SL

Table 1. Responses from medical students to the questionnaire regarding SL sessions.

\begin{tabular}{|c|c|c|c|c|c|c|}
\hline \multirow[t]{2}{*}{ Questionnaire Item } & \multicolumn{2}{|c|}{$\begin{array}{c}\text { Agree } \\
\text { (Score: } 5 \text { and } 4)\end{array}$} & \multicolumn{2}{|c|}{ Neutral (Score: 3) } & \multicolumn{2}{|c|}{$\begin{array}{c}\text { Disagree } \\
\text { (Score: } 2 \text { and } 1)\end{array}$} \\
\hline & No. & $\%$ & No. & $\%$ & No. & $\%$ \\
\hline $\begin{array}{l}\text { SL were better than fulfilling } \\
\text { learning objectives }\end{array}$ & 79 & 71.82 & 15 & 13.64 & 16 & 14.55 \\
\hline $\begin{array}{c}\text { SL can mobilize your enthusiasm } \\
\text { of learning HE }\end{array}$ & 82 & 74.55 & 12 & 10.91 & 16 & 14.55 \\
\hline $\begin{array}{c}\text { SL can deepen understanding of } \\
\text { what you learn }\end{array}$ & 78 & 70.91 & 14 & 12.73 & 18 & 16.36 \\
\hline $\begin{array}{l}\text { SL can enhance your learning } \\
\text { responsibility }\end{array}$ & 86 & 78.18 & 13 & 11.82 & 11 & 10.00 \\
\hline $\begin{array}{l}\text { SL can improve your } \\
\text { communication and } \\
\text { expression skills }\end{array}$ & 81 & 73.64 & 9 & 8.18 & 20 & 18.18 \\
\hline $\begin{array}{l}\text { SL can improve your self-learning } \\
\text { ability and independent thinking }\end{array}$ & 75 & 68.18 & 7 & 6.36 & 28 & 25.45 \\
\hline $\begin{array}{l}\text { SL can improve your ability of } \\
\text { literature retrieval and utilization }\end{array}$ & 66 & 60.00 & 5 & 4.55 & 39 & 35.45 \\
\hline $\begin{array}{l}\text { SL can improve your ability to } \\
\text { analyze and solve problems } \\
\text { synthetically }\end{array}$ & 72 & 65.45 & 8 & 7.27 & 30 & 27.27 \\
\hline $\begin{array}{l}\text { SL can help to develop your } \\
\text { critical thinking }\end{array}$ & 76 & 69.09 & 6 & 5.45 & 28 & 25.45 \\
\hline
\end{tabular}

1) Responses were scored using a five-point Likert scale, where $5=$ strongly agree, $4=$ agree, $3=$ neutral, $2=$ disagree, and 1 = strongly disagree. 2) SL, sandwich learning. 
Table 2. Comparison of the results in the experimental group and the control group ( $\bar{x} \pm s$, points).

\begin{tabular}{cccc}
\hline Performance & Control group $(\mathrm{n}=111)$ & Experimental group $(\mathrm{n}=110)$ & $P$ \\
\hline Assignment & $97.94 \pm 1.44$ & $97.19 \pm 2.20$ & 0.003 \\
Specimen evaluation & $71.97 \pm 22.23$ & $72.89 \pm 20.70$ & 0.751 \\
Final exam & $66.17 \pm 11.83$ & $73.01 \pm 11.99$ & 0.000 \\
Total mark & $75.49 \pm 11.02$ & $80.34 \pm 10.79$ & 0.001 \\
\hline
\end{tabular}

in improving learning motivation, to deepen the knowledge of understanding, and enhance learning responsibility and enhance the role of communication skills, and a score of 5 and 4 more than the approval rate of $70 \%$ (Table 2).

\subsection{Comparison of Achievement between Two Groups}

Student achievement included regular assignments (the average of seven assignments), specimen examination, and the final exam (out of 100 points). The total mark of term evaluation $=$ regular assignment $\times 10 \%+$ specimen examination $\times 20 \%+$ final exam $\times 70 \%$ (see Table 2 and Figure 3). The results in Table 2 showed that the experimental group and the control group were significantly different $(P<0.01)$ in all results except for the specimen examination results $(P>0.05)$.

\section{Discussions}

Medical College of Heidelberg University in Germany established the Sandwich Teaching in small classes, which was promoted gradually to the whole university and other medical schools and institutions (Hempel et al., 2016). In China, the study of SL in Chinese Medical schools and universities has been reported applying in some other courses, including Systemic Anatomy (Wang et al., 2012), pathogenic Biology (Ma, Yuan, Zhang, \& Huang, 2016), Neurosurgery (Shi, Zhang, Shi, Chen, \& Ni, 2016), Pathology (Huang, Lu, Luo, \& Zhang, 2018), Epidemiology (Wang, Jia, Lu, Han, \& Li, 2017), Pharmacology (Lu, Zhang, Huang, Wu, \& Cao, 2011), etc.

Our results showed that there were differences between the grades of experimental group and the control group, which was consistent with the results of reported teaching studies in some of above the courses. Our SL survey results are consistent with their findings in terms of playing a positive role in improving students' learning ability.

\subsection{SL Can Mobilize Students' Learning Motivation, Enhance Their Sense of Responsibility, and Cultivate Expression and Communication Skills}

In SL, students have clear learning objectives, and thus can more fully play to the initiative, self-learning. The students also learn from each other. Each student not only needed to complete the task of this group cooperation, but also bear 


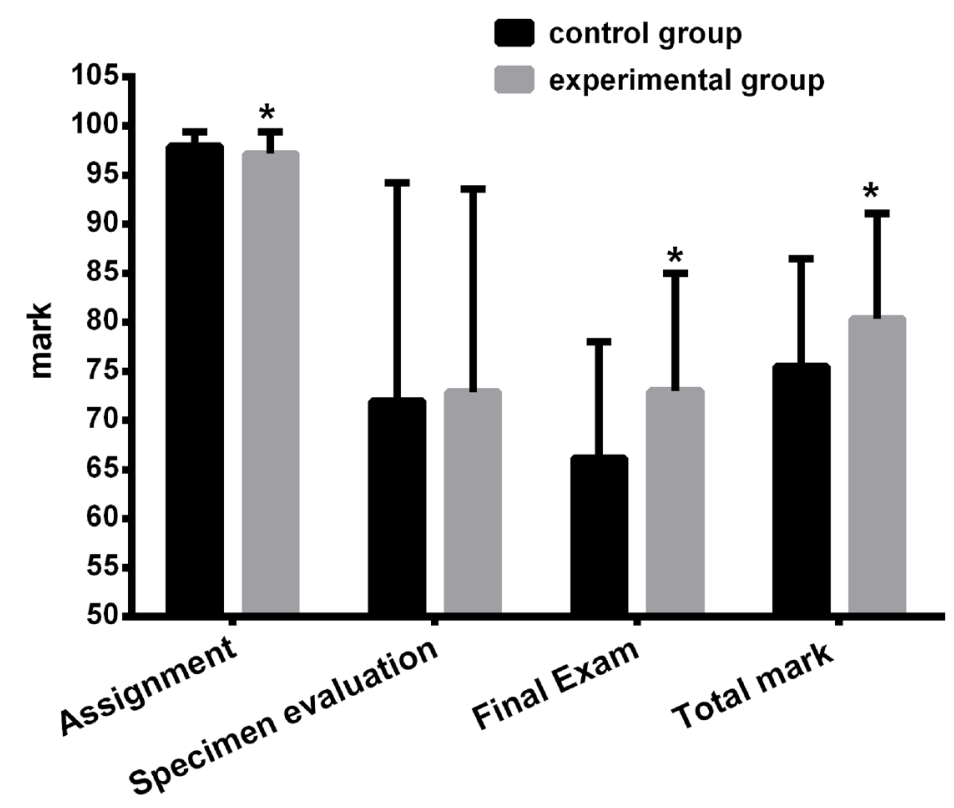

Figure 3. Comparison of the results in the experimental group and the control group. ${ }^{\star}$ Compared with the control group, $P<0.01$.

responsibility for tutoring other students, which helps the students to understand the learning content, developed the communication and collaboration capabilities. Mutual understanding and interactions are better than traditional classroom situation by prolonged contact. SL process trains the students' communication skills, expression skills, autonomous learning ability and the ability to work with others.

\subsection{Sandwich Learning Is Conductive to Cultivating Student's Ability of Analyzing and Solving Problems and Solving Problems}

When students get the question, they must analyze issues; discuss solutions to problems, taking into account discussions in this group to get answers to withstand questioning other groups of students. In group discussions, brainstorming, find information, answer questions drawn process, and improve the ability to solve problems. In the cross-learning phase, students answer questions in the analysis while developing critical thinking, so thinking more clearly, more scientific conclusions. Student-centered and self-directed learning occurred; students monitored their own learning progress and evaluated their success in achieving their learning objectives. Students received faculty and peer feedback. The class sessions were used exclusively for the assessment and application of knowledge through case-based discussions.

A growing amount of evidence from different disciplines is supported the efficacy of active learning (Antepohl \& Herzig, 1999; Obad et al., 2016; Pogge, 2016; Seidel \& Richards, 2001; Thomas \& Bowen, 2011). Our experience in implementing a SL approach that created an appropriate active learning environment was well received, according to both student and teacher feedback. Also, by 
the virtue of this feedback, we still continue to adjust various aspects of the course. The responses of students in this study indicate that most of the students preferred the modified SL method to the traditional lecture method. SL can be a highly effective tool in terms of training in data analysis together with problem solving using teamwork. Designing effective group assignments helps to maximize the extent to which the learning tasks promote the development of cohesive learning groups. The single best way to gauge the effectiveness of group assignments is observing the level of energy that is present when the results of the small-group discussions are reported to the class as a whole. Communication skills that are essential for physicians are developed by this method.

Compared with traditional lecture-based teaching (LBL), Sandwich learning has more advantages. However, due to the limit of time and place, students can not sufficiently and comprehensively retrieve documents, which confine the discussed questions to narrow and shallow level and make the discussion and solution limited.

Due to limited time in the classroom, we suggest that the problem should be arranged in advance to the study group, let them searching the information and discussing the questions in extra-curricular time. In this way, students can directly cross-study in the classroom, improving the ability of depth of data analysis, integration and discussion.

\section{Conclusion}

We demonstrated that SL has certain advantages by higher participation of students. It was inserted by students' group discussion, cross learning and study reports, etc., which can encourage students to have more communications with teachers and other students so as to improve students' abilities of self-learning, thinking and exploring new knowledge. Therefore, sandwich learning has the advantages as team-based learning (TBL) in which inquiry teaching stimulates students' initiative study (Obad et al., 2016; Pogge, 2016; Seidel \& Richards, 2001; Thomas \& Bowen, 2011). The downside is that the cross-learning discussion during sandwich teaching is a bit noisy because of the large number of classes, which has a little impact on the learning effect. Thus, Sandwich Learning is suitable to be occasionally used for large-scale class.

\section{Disclosures}

No conflicts of interest, financial or otherwise, are declared by the authors.

\section{Funding}

Guangxi Zhuang Autonomous Region Higher Education Reform Project of China: Guijia Higher Education [2014] No. 15 (NO. 2014JGZ135); Guijia Higher Education [2017] No. 32 (NO. 2017GJB343).

\section{References}

Antepohl, W., \& Herzig, S. (1999). Problem-Based Learning versus Lecture-Based Learn- 
ing in a Course of Basic Pharmacology: A Controlled, Randomized Study. Medical Education, 33, 106-113. https://doi.org/10.1046/j.1365-2923.1999.00289.x

Hempel, D., Haunhorst, S., Sinnathurai, S., Seibel, A., Recker, F., Heringer, F., Michels, G., \& Breitkreutz, R. (2016). Social Media to Supplement Point-of-Care Ultrasound Courses: The "Sandwich e-Learning" Approach: A Randomized Trial. Critical Ultrasound Journal, 8, 3. https://doi.org/10.1186/s13089-016-0037-9

Huang, Y., Lu, H., Luo, B., \& Zhang, S. (2018). Application Experience of "Sandwich" Teaching Mode in Pathology. Journal of Frontiers of Medicine, 7, 390-391. (In Chinese)

Huang, Y., Ma, J., Yi, X. P., \& Fu, C. C. (2008). Sandwich Learning in Medical Education. Medicine and Society, 3, 55-56. (In Chinese)

Kadmon, M., Strittmatter-Haubold, V., Greifeneder, R., Ehlail, F., \& Lammerding-Koppel, M. (2008). The Sandwich Principle-Introduction to Learner-Centred Teaching/Learning Methods in Medicine. Zeitschrift fur Evidenz, Fortbildung und Qualitat im Gesundheitswesen, 102, 628-633. https://doi.org/10.1016/j.zefq.2008.11.018

Kay, D., \& Kibble, J. (2016). Learning Theories 101: Application to Everyday Teaching and Scholarship. Advances in Physiology Education, 40, 17-25.

https://doi.org/10.1152/advan.00132.2015

Lu, Y., Zhang, Z., Huang, Y., Wu, J., \& Cao, J. (2011). The Application of Sandwich Teaching Method in the Teaching of Pharmacology. Journal of Hubei University of Chinese Medicine, 3, 77-78. (In Chinese)

Ma, C., Yuan, Z., Zhang, X., \& Huang, J. (2016). Practice of "Sandwich" Teaching Combined with Traditional Teaching in the Teaching of Pathogenic Biology. Journal of Guangzhou Medical University, 1, 80-82. (In Chinese)

McKeachie, W. J., Svinicki, M. D., \& Hofer, B. K. (2006). McKeachie’s Teaching Tips: Strategies, Research, and Theory for College and University Teachers (12th ed.). Boston: Houghton Mifflin.

Obad, A. S., Peeran, A. A., Shareef, M. A., Alsheikh, W. J., Kalagi, D. A., AlAmodi, A. A., Khan, T. A., Shaikh, A. A., Ganguly, P., \& Yaqinuddin, A. (2016). Assessment of First-Year Medical Students' Perceptions of Teaching and Learning through Team-Based Learning Sessions. Advances in Physiology Education, 40, 536-542. https://doi.org/10.1152/advan.00001.2016

Piaget, J. (1997). The Principles of Genetic Epistemology. London, New York: Routledge.

Pogge, E. (2016). Evaluation of an Interprofessional Team-Based Learning Nutrition and Lifestyle Modification Course. Journal of Interprofessional Care, 30, 248-250. https://doi.org/10.3109/13561820.2015.1092118

Salter-Dvorak, H. (2016). Learning to Argue in EAP: Evaluating a Curriculum Innovation from the Inside. Journal of English for Academic Purposes, 22, 19-31. https://doi.org/10.1016/j.jeap.2015.12.005

Seidel, C. L., \& Richards, B. F. (2001). Application of Team Learning in a Medical Physiology Course. Academic Medicine, 76, 533-534. https://doi.org/10.1097/00001888-200105000-00071

Shi, J., Zhang, Y., Shi, W., Chen, J., \& Ni, L. (2016). Application and Evaluation of Sandwich Teaching Method in Clinical Teaching in the Department of Neurosurgery. Chinese Journal of Medical Education Research, 10, 1039-1041. (In Chinese)

Thomas, P. A., \& Bowen, C. W. (2011). A Controlled Trial of Team-Based Learning in an Ambulatory Medicine Clerkship for Medical Students. Teaching and Learning in Medicine, 23, 31-36. https://doi.org/10.1080/10401334.2011.536888 
Wang, C., Zhou, H., Li, Z., Zhao, H., Cai, R., \& Xu, C. (2012). Experience in the Preparation of the Teaching Plan of the Systematic Anatomy of the Sandwich Teaching Method. Journal of Regional Anatomy and Operative Surgery, 1, 103-104. (In Chinese)

Wang, J., Li, H., Luo, C., Chen, J., Fang, X., Zhao, Q., Huang, Q., \& Li, W. (2015). Application and Practice of sandwich Teaching Method in Histology and Embryology Experiment Teaching. Chinese Journal of Anatomy, 6, 752-754. (In Chinese)

Wang, P., Jia, G., Lu, P., Han, W., \& Li, J. (2017). Implementation of Sandwich Teaching Concept in Case Teaching of Epidemiology. Basic Medical Education, 2, 114-116. (In Chinese) 